\title{
Europa y el rescate de cautivos en el Mediterráneo durante la temprana Edad Moderna
}

\author{
José Antonio Martínez Torres \\ UNED, Madrid
}

\section{Europe and captives' ransom in the Mediterranean during the Early Modern Age}

\begin{abstract}
RESUMEN ABSTRACT
Este trabajo, basado en importantes fuentes primarias y secundarias, se ocupa de la vida y el rescate de los miles de europeos apresados por los corsarios berberiscos en el Mediterráneo y el Atlántico durante los siglos XVI y XVII.

PALABRAS CLAVE: Rescate de cautivos europeos / corsarios berberiscos.

This work, based on important primary and secondary sources, is about the life and rescue of the thousand of Europeans made prisoners by the Berber corsairs in the Mediterranean and the Atlantic during the 16th and 17th centuries.

KEYWORDS:

Rescue of Europeans captives / Berber corsairs.
\end{abstract}

Las treguas que acordaron entre 1581 y 1587 los plenipotenciarios de Felipe II y de Murat III y sus aliados, los regentes turcos de Argel, Túnez y Trípoli, oficialmente ponían fin a la larga pugna que por el control del Mediterráneo venían manteniendo ambos imperios desde 1516, fecha en la que Carlos $V$ hereda el trono español y Hayredin Barbarroja es proclamado beylerbey de Argel ${ }^{1}$. Sin embargo, estas negociaciones de paz no contemplaban la liberación de todas aquellas personas que, fruto de la guerra terrestre o marítima, se encontraban prisioneras en las poblaciones de Turquía y el norte de África. Con tales treguas los soberanos de ambos imperios se comprometían a abandonar el frente del Mediterráneo, la

1 Archives du Ministère des Affaires Étrangères, (AMAE), Fonds Divers-Memories et Documents, (Turquie), leg. 7, «Traités conclus par la Turquie avec La France, L’Espagne, Venise et Les Pays Bas», 1528-1612. 
tradicional zona de hostilidad entre el Occidente cristiano y el Islam, para concentrarse en sus problemas políticos más urgentes. Para el monarca hispano eran los protestantes del norte de Europa, y para el sultán otomano los musulmanes que ocupaban el trono de Persia².

Sin ánimo de restar importancia a los hechos mencionados arriba, no debemos olvidar que la supresión de las grandes batallas mediterráneas también normalizó el comercio de cereales, textiles, especias, cueros, etc. En este sentido, se puede decir que en el Mediterráneo de finales del siglo XVI se consolidó y hasta potenció una importante zona de mercados y circuitos comerciales, muchos de ellos clandestinos y todavía pendientes de estudio. Se tratara de expediciones de rescate de esclavos o de comerciantes en busca de nuevos productos y mercados, lo cierto es que desde principios del siglo XVII se incrementaron los viajes al norte de África, Turquía y el África occidental y oriental, todo debidamente asegurado por compañías mercantiles genovesas, inglesas, francesas y holandesas, que obtenían con este tráfico unos importantes beneficios ${ }^{3}$. Ahora bien, al mismo tiempo que se desencadenaba este proceso, la inseguridad en la navegación del Mediterráneo y el Atlántico aumentaba en la misma escala.

En palabras de Fernand Braudel, la «gran guerra», caracterizada por su elevado gasto económico y por sus espectaculares despliegues militares, era sustituida por la «pequeña guerra» o «guerra corsaria», considerablemente menos costosa pero de mayor efectividad y beneficios. Ciudades como Djidjelli, Túnez, Argel, Bugía, Tetuán y Salé, esta última ubicada en la fachada occidental del reino de Marruecos y con una población próxima a los 10.000 moriscos expulsados de Extremadura, Castilla y la Baja Andalucía entre 1609 y 1614, decidieron aprovechar que las potencias cristianas luchaban entre sí para romper unilateralmente las treguas acordadas en los últimos decenios del siglo XVI y capturar un importante número de barcos, mercancías y personas ${ }^{4}$. Sadok Boubaker, historiador que se ha ocupado de las relaciones comerciales entre los puertos de Túnez, Marsella y Livorno en el siglo XVII, ha proporcionado algunas muestras de las ganancias obtenidas en tales asaltos. Gracias a este trabajo sabemos que, entre 1652 y 1665 , los corsarios tunecinos se apoderaron de un botín compuesto por 18 barcos europeos y una serie de mercancías cuyo valor ascendía a 1.080.000 libras torne$\operatorname{sas}^{5}$. Aunque desgraciadamente nunca conoceremos el número exacto de europeos apresados por los corsarios berberiscos en las poblaciones bañadas por el

${ }^{2}$ F. Braudel, El Mediterráneo y el Mundo Mediterráneo en tiempos de Felipe II, México, Fondo de Cultura Económica, 1976, II, pp. 501 y ss.

3 Ibidem, II, pp. 315-317; J. ROMERO MAgalHÂES, «As incursões no espaço africano», en F. BETHENCOURT y K. ChaudHuRI (dirs.), História da expansão portuguesa, Lisboa, Círculo de Leitores, 1998, II, pp. 65-81; C. Martínez Shaw y M. Alfonso Mola, Europa y los Nuevos Mundos en los siglos XV-XVIII, Madrid, Síntesis, 1999, pp. 21 y ss.

${ }_{4}^{4}$ S. Bono, Corsari nel Mediterraneo. Cristiani e musulmani fra guerra, schiavitù e comercio, Milán, Arnoldo Mondadori, 1993.

${ }^{5} \mathrm{~S}$. BOUBAKER, La Régence de Tunis au XVII siècle: les relations commerciales avec les ports de l'Europe méditerranéenne, Marseille et Livourne, Zaghouan, CEROMA, 1987, pp. 44, 45 y ss. 
Mediterráneo y el Atlántico, podemos hacernos una idea de su elevado número gracias a las sumas que ha publicado Robert C. Davis 6 . Sabemos, por ejemplo, que entre 1582 y 1690 los corsarios berberiscos capturaron un total de 49.460 cautivos (casi 458 anuales), la mayoría de ellos en las costas de Italia, Francia, España, Portugal e Inglaterra.

Desde Grecia a Islandia pasando por Inglaterra, un importante número de localidades costeras fueron arrasadas por los corsarios del norte de África en rápidos y eficaces golpes de mano. El caso de Plymouth es muy ilustrativo al respecto, pues sólo en un año, 1625, los berberiscos capturaron a más de un millar de habitantes de esta localidad del sudoeste inglés en un radio de acción que no superaba las 30 millas de costa. Como certeramente ha subrayado John $\mathrm{H}$. Elliott, la política de no beligerancia que acordaron Jacobo I de Inglaterra y Felipe III de España favorecía un acercamiento entre ambas monarquías gracias a un futuro matrimonio entre el príncipe de Gales y la infanta María, la hija menor de Felipe III y Margarita de Austria $^{7}$. Ahora bien, esta particular política arrastraba a Inglaterra a contraer los mismos enemigos que España. Disponemos de cifras que corroboran esta afirmación. Entre 1600 y 1640, por ejemplo, los corsarios berberiscos capturaron más de 800 navíos ingleses e hicieron alrededor de 13.000 prisioneros. El hostigamiento a las costas inglesas por los marinos berberiscos fue de tal calibre, que Carlos I no tuvo más remedio que elevar el impopular "ship money", tasa destinada a equipar la Armada inglesa, para conseguir frenar estos ataques. Como colofón podemos indicar que la huella del Islam en la Inglaterra postisabelina fue mayor de lo que tradicionalmente se pensaba, como refleja el estreno de piezas de teatro sobre el rescate de cautivos en el teatro del Covent Garden o la celebración de naumaquias que enfrentaban a una ficticia flota cristiana contra otra musulmana ${ }^{8}$.

La penetración de la mentalidad de la Contrarreforma en las monarquías europeas más afectadas por las razzias berberiscas motivó que los monarcas no pasaran por alto las solicitudes de rescate que cursaron sus súbditos cautivos ${ }^{9}$ a través de los diferentes órganos que componían el aparato político-gubernamental durante esta época. En lo que a España, Francia y Portugal se refiere, es posible afirmar sin riesgo de error que las iniciativas de rescate de las órdenes de la Trinidad y la Merced $^{10}$, máximas responsables en libertar cristianos en los territorios

6 R. C. DAvis, «Counting european slaves on the Barbary Coast», Past and Present, 172, (2001), pp. 87-124 (en particular pp. 91-93).

7 J. H. ElLiott, El Conde-Duque de Olivares, Barcelona, Crítica, 2004, pp. 239-250.

8 L. Colley, Captives: Britain, Empire and the World, 1600-1850, Londres, Jonathan Cape, 2002, pp. 43, 49-50; R. C. Davis, Christian slaves, Muslim masters: White slavery in the Mediterranean, the Barbary Coast and Italy, 1500-1800, Nueva York, Palgrave, 2003, p. 3; J. GoodY, L'Islam en Europe. Histoire, échanges, conflits, París, Éditions La Découverte, 2004, p. 52.

9 AmAE, Fonds Divers-Memories et Documents, (Afrique), leg. 8, «Supplique de six esclaves de Tunis», 1631.

10 R. Grimaldi-HieRHoltz, L'ordre des Trinitaires, París, Fayard, 1994; B. TAYLOR, Structures and Reform: The Mercedarian Order in the Spanish Golden Age, Leiden, Brill, 2000, (mi agradecimiento a John H. Elliott por esta referencia). 
de Islam prácticamente desde su fundación, en los siglos XII y XIII respectivamente, estuvieron inscritas en una política dictada por los Habsburgos españoles y los Borbones franceses, acorde a los intereses políticos que ambas dinastías mantuvieron en el Mediterráneo a lo largo de toda la Edad Moderna ${ }^{11}$. Felipe II y Luis XIII sentaron las bases de la colaboración que iban a mantener sus respectivos sucesores en el trono con los religiosos de la Trinidad y la Merced hasta finales del siglo XVIII, momento en que ambas órdenes fueron suprimidas por la legislación revolucionaria ${ }^{12}$. Es muy difícil saber el número de personas rescatadas por los religiosos, pues la documentación se encuentra muy deteriorada y las cifras varían mucho dependiendo del archivo y la fuente de estudio ${ }^{13}$. No obstante, podemos indicar que los mercedarios y los trinitarios de España, Francia y Portugal rescataron a un total de 19.299 cautivos en 96 operaciones (75 eran trinitarias y 21 mercedarias) efectuadas en Marruecos y Argel entre 1539 y $1696^{14}$.

Parafraseando a Bernard Vincent, el carácter casi monopolístico que en las negociaciones de rescate de cautivos desempeñaron para los gobiernos de España, Francia y Portugal los religiosos de la Trinidad y la Merced no debe hacernos olvidar que tales operaciones fueron sólo una pequeña parte del inmenso iceberg de procedimientos de rescate e intermediarios que existieron en el Mediterráneo de los siglos XVI y XVII ${ }^{15}$. La mayor parte de las personas que optaban por las redenciones religiosas sabían que eran una vía para alcanzar la libertad pero no necesariamente la más rápida ni la más segura. Una prueba del relativo éxito que obtuvieron los religiosos lo demuestran los abundantes testimonios de familiares de cautivos que, desde las localidades saqueadas por los corsarios berberiscos, se desplazaron hasta la Corte de Madrid para solicitar del monarca un dinero a préstamo o un turco, moro o morisco con el que libertar un familiar o amigo que estaba prisionero en el norte de África ${ }^{16}$.

Las autoridades de Génova, Nápoles y Palermo, probablemente los territorios italianos más afectados por las razzias berberiscas, decidieron rescatar a sus prisioneros en el norte de África de una manera muy distinta a los gobiernos de Es-

11 J. Carpentier y F. Lebrun (dirs.), Histoire de la Méditerranée, París, Seuil, 1998, pp. 213-300 (colaboración de Bartolomé Bennassar).

12 Archives Nationales de France, (ANF), G9 22, ANF, G $^{9} 23$.

13 R. GRIMALDI-HIERHOLTZ, L'ordre des Trinitaires..., p. 69.

14 Archivo Histórico Nacional de Madrid, (AHN), Códices, (Cód.), legajo, (leg.), 117, 118, 119, 120, $121,122,123,124,125,126,127,128,129,130,131,132,133,134,135,136,137,138,139,140,141$, 142, 143, 144, 146, 147; Biblioteca Nacional de Madrid, (BNM), Manuscritos, (mss.), 2.727, 2.963, 2.974, 3.634, 3.862, 3.870, 3.872, 4.359, 4.363, 4.365, 4.390, 6.160, 6.569; Bibliothèque Nationale de France, (BNF), Ld. 43-5, 43-18, 43-19, 43-30, 43-35, 44-3, 44-4, 44-6, 44-8. Las cifras portuguesas han sido extraídas del trabajo de I. Mendes Drumond Braga, Entre a Cristiandade e o Islâo (seculos XV-XVII) Cativos e Renegados nas Franjas de duas Sociedades em Confronto, Ceuta, Instituto de Estudios Ceutíes, 1998, pp. 219-221 y 238.

15 B. VINCENT, «Procédures et réseauX de rachats de captifs dans l'Espagne des XVle-XVIle siècles», en W. KaISER (ed.), Les intermédiaries dans l'échange et le rachat des captifs en Méditerranée, XVIeXVIle siècles, Rome, École française de Rome, 2005 (en preparación).

16 Archivo General de Simancas (AGS), Comisaría de Cruzada, legajos 286, 287 y 288. 
paña, Francia y Portugal. A diferencia de tales estados, que se valieron como hemos visto de las redenciones de la Trinidad y la Merced para libertar a una parte de sus cautivos, las autoridades italianas prefirieron hacer uso de archicofradías, magistraturas y compañías de mercaderes cuyos orígenes en muchos casos se remontaban al siglo $\mathrm{XIII}^{17}$. Aunque es cierto que los lazaristas y los capuchinos efectuaron rescates para algunos territorios italianos ${ }^{18}$, las archicofradías y las compañías de mercaderes fueron las que verdaderamente monopolizaron los rescates a Berbería gracias al apoyo de los Papas (entre 1566 y 1692 redactaron un total de 6.000 cartas a favor de las colectas para el rescate de cautivos), la nobleza y los familiares de los cautivos. Del amplio número de instituciones de rescate que, desde principios del siglo XVI proliferaron por toda la Península italiana, son destacables la archicofradía Gonfalone de Roma (1260-1267), la archicofradía Santa María de las Nieves de Bolonia (1518), la Real Casa Santa de la redención de cautivos de Nápoles (1548), la Diputación para el rescate de cautivos de Palermo (1585) y la Magistratura para el rescate de cautivos de Génova (1597) ${ }^{19}$. La más importante de todas estas instituciones fue, sin ningún género de dudas, la archicofradía Gonfalone de Roma, que, impulsada por el Papa Gregorio XIII, llegó a libertar a 271 prisioneros en Argel entre 1585 y 1589. A partir de 1590 sus datos son muy fragmentarios, lo que nos impide saber el total de personas rescatadas en los siglos XVI y XVII. El mismo fenómeno afecta al resto de las instituciones mencionadas: conocemos el número de cautivos rescatados en momentos cronológicos precisos, pero no disponemos de series que puedan compararse a las ofrecidas por los religiosos de la Merced y la Trinidad.

Inglaterra y las Provincias Unidas tampoco fueron ajenas a los rescates de cautivos en las poblaciones norteafricanas. Al principio de este trabajo ya indicamos que una importante suma de personas procedentes del norte de Europa fueron capturadas por los berberiscos como fruto de su penetración comercial en el Mediterráneo de finales $\left.X V\right|^{20}$. Hasta la fecha no disponemos de estudios sobre las negociaciones de rescate de las Provincias Unidas, aunque sabemos que utilizaron la intermediación de cónsules y mercaderes ${ }^{21}$. El caso inglés está mejor documentado gracias a una serie de trabajos que han aparecido recientemente. Como consecuencia directa de los virulentos ataques corsarios a las costas del sudoeste inglés en la primera mitad del siglo XVII, los habitantes de tales localidades de-

17 S. Bono, Corsari nel Mediterraneo..., pp. 204-206.

$18 \mathrm{M}$. MAFRICI, «I meridionali schiavi dei Turchi e l'azione dei Cappucini», en V. CRIscuolo (dir.), I frati minori cappucini in Basilicata en el Salernitano fra '500 e '600, Roma, Istituto Storico dei Cappucini, 1999.

19 G. Boccadamo, La redenzione dei Cattivi a Napoli nel Cinquecento, Nápoles, M. D'Auria Editore, 1985; E. LuccINI, La merce umana. Schiavitù e riscatto dei Liguri nel Seicento, Roma, Bonacci Editore, 1990; A. Romano, La deputazione per la redenzione dei cattivi di Palermo (1585-1714), Tesi di laurea, Università degli Studi di Palermo, 2000-2001.

20 M. GREENE, «Beyond the Northern invasion: the Mediterranean in the seventeenth century», Past and Present, (2002), pp. 42-71.

21 G. van KRIEKEN, Corsaires et marchandes. Les rélations entre Alger et les Pays-Bas, 1604-1830, París, Bouchene, 2002. 
cidieron presionar a sus autoridades civiles y religiosas para que se hicieran campañas de rescate. Desde mediados del siglo XVII hasta finales del siglo XVIII, un comité de tres personas (un miembro de la familia real, el arzobispo de Canterbury y el obispo de Londres) presidido por los representantes de las Cinco Naciones (Bretaña, Escocia, Gales, Inglaterra e Irlanda) y apoyado por el Privy Council alentaba a los párrocos ingleses a sermonear sobre los «horrores de Berbería», recaudaba la limosna y se encargaba de entablar las negociaciones de rescate. Tenemos constancia de cinco importantes operaciones efectuadas entre 1660 y 1700 , aunque no del total de cautivos libertados. Una de las campañas más importantes fue la organizada en 1680, que llegó a recuperar a 730 habitantes de la pequeña localidad de Tavistock por 11.680 libras. Al igual que los españoles, los franceses, los portugueses y los italianos, los ingleses dieron muestras de una enorme "people's charity", ofreciendo cuantiosas limosnas y participando en procesiones de fuerte coreografía congratulatoria y patriótica en las calles próximas a la catedral de San Pablo22.

En definitiva, en uno de los escasos balances de población cautiva que se han realizado hasta la fecha, se menciona que entre 1.000 .000 y 1.250 .000 de europeos permanecieron retenidos en las poblaciones del norte de África a lo largo de toda la Edad Moderna ${ }^{23}$. La mayor parte de estos cautivos eran originarios de las poblaciones costeras del Mediterráneo y el Atlántico, resultado de una guerra no declarada, extraordinariamente presente en la memoria colectiva de los europeos desde las décadas finales del siglo XVI, momento de reactivación del corso berberisco, hasta nuestros días, época marcada por el «choque de civilizaciones» si nos hacemos eco de las discutibles tesis que lanzaron algunos politólogos a finales del siglo pasado. Ninguno de los capitanes corsarios que asolaron en el pasado las costas europeas buscaba la conquista de vastos territorios para el sultán de la Sublime Puerta, el rey de Marruecos o el Consejo de doce miembros que gobernaba la «República de Salé». Al contrario, los corsarios musulmanes siempre trataron de hacer el mayor daño posible a todos los enemigos de su fe de una manera rápida y sistemática. En la mentalidad del prisionero europeo la pérdida de libertad se considera una desgracia inexplicable, mientras que en la lógica de los captores todas las personas apresadas en los asaltos eran vistas como una importante ganancia por tres razones fundamentales: por el trabajo que podían desempeñar, por el precio a pagar por sus rescates e incluso por su venta como esclavos.

\section{TRABAJOS, FUGAS Y MUERTES}

En las poblaciones del norte de África, lo mismo en las costeras que en las del interior, los europeos capturados por los berberiscos eran diferenciados en tres

22 L. Colley, Captives..., pp. 75-81.

23 R. C. Davis, Christian slaves..., p. 23. 
categorías. Aproximadamente una octava parte de todos los cautivos que desembarcaban en los puertos berberiscos eran escogidos para la máxima autoridad de gobierno. Estos cautivos eran conocidos como cautivos «del rey» 0 «forzosos" y siempre fueron objeto de rescate, independientemente de su alto precio de venta. El segundo escalón en esta pirámide lo ocupaban los cautivos comprados en los mercados de esclavos por acaudalados musulmanes, judíos y moriscos expulsados de Europa entre mediados del siglo XV y principios del XVII. Estos cautivos eran conocidos como «aguatis» $y$, al igual que los cautivos «del rey» 0 «forzosos», también podían ser comprados por los redentores de la Merced y la Trinidad. El último escalón de esta pirámide lo ocupaban los cautivos que no tenían dueño, los cautivos del «almacén» o «concejo». Aunque tales cautivos eran los más demandados por los redentores (la mayor parte de la limosna que recogían iba destinada a ellos), nunca pudieron rescatarse porque estaban condenados a trabajar a perpetuidad. Es más, estos cautivos fueron divididos en otras tres categorías («caravanas», «maestranzas» y «pasabarros») dependientes del trabajo a realizar (boga en galeras, construcción de barcos y trabajos de albañilería respectivamente).

Excepto las mujeres y los niños, que trabajaban y dormían en los domicilios de sus propietarios, los cautivos adultos eran los únicos que vivían en el interior de los baños. Sin ánimo de entrar a valorar la vieja polémica que existe a propósito del significado y la procedencia de esta curiosa palabra ${ }^{24}$, sin duda muy útil para otros ámbitos de estudio, hay que subrayar que los baños que había en el norte de África en esta época eran unos edificios subterráneos de una, dos y hasta tres plantas, con habitaciones con capacidad para más de veinte personas, y con pequeños hospitales, capillas y fonduks o tabernas donde los cautivos podían comprar bebida y alimentos. Ignoramos el número de baños que hubo en Marruecos en el siglo XVII, pero sabemos, en cambio, que en Argel, Túnez y Trípoli en la misma centuria hubo 18 baños y un total de 15.559 cautivos, la mayoría de ellos apresados en las costas del sur de Europa ${ }^{25}$.

El aumento del número de cautivos que se produjo en todas las poblaciones del norte de África entre el último tercio del siglo XVI y la primera mitad del siglo XVII convirtió el mantenimiento del orden público en una verdadera obsesión para los captores. En lo que respecta a los baños, esta tarea recaía en un renegado conocido como el «guardián-basci». Algunas de las competencias del «guardián-basci» eran seleccionar a los cautivos que no eran de rescate para sus trabajos en el exterior (desbroce de acequias, recogida de piedras, etc.), proporcionar comida para todo el día (sémola de trigo y habas secas) y ordenar la limpieza del baño a los cautivos que eran considerados «de rescate» (llevaban una cadena al-

${ }_{24}$ G. AuDISIO, «Recherches sur l'origine et la signification du la mot `bagne'», Revue Africaine, Cl, (1957), pp. 363-380.

25 S. Bono, I corsari barbareschi, Turín, RAI, 1964, pp. 220-221 y 228; P. SebaG, Tunis au XVIIe. Une cité barbaresche au temps de la course, París, L'Harmattan, 1989, pp. 127-130. 
rededor del cuello como atributo de distinción, no de castigo). Cuando los cautivos regresaban de sus tareas, el «guardián-basci» comprobaba si faltaba algún cautivo y cerraba las puertas del baño. El miedo a la muerte, los brutales castigos (los bastonazos en el vientre y en las plantas de los pies eran los más frecuentes) y la introducción de cautivos delatores o «parleros» (tenían la promesa de obtener su libertad al tercer año de prestar este servicio) contribuían al sometimiento de los prisioneros $^{26}$.

A pesar de todos estos esfuerzos, las autoridades berberiscas no pudieron evitar que los cautivos se rebelaran a su condición planeando rebeliones y evasiones a tierras europeas. La documentación que hemos consultado proporciona ejemplos de fugas extraordinariamente meditadas, motivadas en cierto modo por las recompensas ofrecidas por las autoridades civiles y religiosas. Un ejemplo de esto último lo ofrecen Curcio Papante y Miguel Bocanotra, dos cautivos italianos que entre 1578 y 1590 sirvieron en Argel a un moro «muy rico y poderoso... casado con una gentil dona griega cristiana». Tras doce años de reclusión muy adversa, ambos cautivos decidieron envenenar a su propietario y huir a Roma, pues sabían que el Papa Sixto V solía premiar las fugas realizadas por los cautivos italianos ${ }^{27}$. Igualmente, disponemos de fugas mucho más espontáneas, realizadas por cautivos que estaban destinados a una esclavitud a perpetuidad. Un testimonio en esta línea lo ofrece Lorenzo «el jarqui», un galeote de treinta años nacido en Almarax (Almería) en 1514, que declaró a los oficiales del Consejo de Guerra hispano haber «saltado al Cabo de Palos» aprovechando un descuido del renegado que capitaneaba la fusta en la que él bogaba ${ }^{28}$.

No resulta difícil imaginar, al hilo de todo lo que se ha señalado aquí, que la muerte de un cautivo europeo fue relativamente habitual en las diferentes poblaciones norteafricanas. La peste y el tifus eran las causas de fallecimiento más frecuentes entre la población cautiva y entre la autóctona. No obstante, los cautivos también podían morir por disentería, agotamiento y severas fracturas de huesos causadas por sus propietarios. Desconocemos la cifra global de los cautivos que fallecieron por todos estos motivos en Argel, Túnez y Trípoli durante todo el siglo $\mathrm{XVII}$, pero tenemos algunos datos para Meknés (Marruecos) a finales de la misma centuria ${ }^{29}$. A pesar del carácter fragmentario de la muestra ofrecida, sabemos que en dicha localidad marroquí, entre 1684 y 1699, fallecieron 1.297 cautivos (casi 87 diarios) por las enfermedades indicadas.

26 G. Gómez de Losada, Escuela de trabajos, Madrid, Julián Paredes, 1670, folios 52 y ss.

7 AGS, Guerra Antigua, leg. 312, folios 101 y 107.

28 AGS, Guerra Antigua, leg. 27, folio 142.

29 BNM, Sección África, (Fondo García Figueras), 7.782, «Cristianos cautivos muertos en Berbería de 1684 a $1779 », 120$ folios. 


\section{LAS NEGOCIACIONES DE RESCATE: LOS EJEMPLOS DE ESPAÑA Y FRANCIA}

En la correspondencia que nos han dejado en los archivos españoles y franceses los religiosos de la Trinidad y la Merced podemos apreciar que los Padres provinciales de ambas órdenes siempre solicitaron de las autoridades del norte de África una fecha para efectuar el rescate de cautivos y un pasaporte u «otomán» que les garantizara viajar hasta los puertos berberiscos sin las molestias de los corsarios y los bandidos. No son miedos infundados, pues en las proximidades de la ciudad de Argel existían bandas de malhechores que despojaban de ropa y dinero incluso a los europeos menos descuidados. La osadía de los corsarios argelinos fue tal, que es posible encontrar algún que otro caso de naves de la redención que tuvieron que desplegar todo su velamen porque los corsarios querían volver a capturar a los cautivos que habían vendido con anterioridad ${ }^{30}$.

La respuesta de las autoridades del norte de África casi siempre era afirmativa y la comunicación rara vez superaba los seis meses desde que los redentores de la Trinidad y la Merced habían iniciado el proceso negociador. Hay que indicar, no obstante, que el hecho de que los religiosos tuvieran un permiso de rescate rubricado por las autoridades berberiscas no garantizaba su realización. Solamente los monarcas de España y Francia podían convertir lo que hasta ahora se consideraba un proyecto de rescate en una realidad. Los letrados del Consejo de Castilla y los officiers del Conseil d'Etat, respectivamente, eran quienes se encargaban de estudiar la viabilidad de la expedición redentora y de promulgar las cédulas y arrêts que precisaban los religiosos en sus tratos tanto dentro como fuera de Europa $^{31}$.

A diferencia de los monarcas españoles, que proporcionaron a las redenciones religiosas dinero de su propia Hacienda y las integraron en su sistema polisinodial de gobierno después de la victoria naval de Lepanto $(1571)^{32}$, los monarcas franceses prefirieron esperar casi a principios del siglo XVIII para hacer algo semejante. Hasta las décadas finales del reinado de Luis XIV (1661-1715) los reyes de Francia no solicitaron a los religiosos de la Merced y la Trinidad lo mismo que ya habían hecho sus homónimos en España casi cien años antes: oficiales, soldados y marineros capturados en el frente Mediterráneo. La eficacia de los redentores españoles en este particular punto está fuera de toda duda: el $31,13 \%$ de los cautivos rescatados entre 1575 y 1692 con oficio conocido eran militares procedentes del sur de Europa y capturados en guarniciones fronterizas con el Islam ${ }^{33}$.

30 AHN, Cód. leg. 135.

31 BNF, Ld. 43-2.

32 J. A. MARtíneZ TorRes, «El rescate de cautivos cristianos en el norte de África (siglos XVI-XVII)», Historia Social, 49 (2004), pp. 29-48.

33 J. A. Martínez Torres, Prisioneros de los infieles. Vida y rescate de los cautivos cristianos en el Mediterráneo musulmán (siglos XVI-XVII), Barcelona, Bellaterra, 2004, p. 142. 
Igual que hiciera Felipe II en la segunda mitad de su reinado, Luis XIII decidió reglamentar las desordenadas cuestaciones de limosna que venían realizando las órdenes de la Trinidad y la Merced en Francia desde la Edad Media ${ }^{34}$. Esta importante maniobra del primer Borbón fue posible gracias a la colaboración del Parlement de París y el largo centenar de diócesis que estaban repartidas por todo el hexágono francés en esta época. Toda la limosna recaudada en las cuestaciones por los trinitarios y los mercedarios debía centralizarse en los conventos que ambas órdenes tenían en el centro de París desde principios del siglo XIII y XVII respectivamente. No sabemos prácticamente nada de este dinero si exceptuamos el hecho anecdótico de que era custodiado por un religioso de probada confianza en un «arca de tres llaves» a la que sólo tenían acceso otros dos religiosos más, el Padre prior del convento y el Padre provincial de la orden. Tampoco sabemos más sobre su transporte hasta Marsella y Toulon, los puertos más frecuentados por los religiosos franceses para embarcarse al norte de África. Sin embargo, es probable que los redentores hicieran uso de un sistema de letras de cambio de origen templario $^{35}$. El hecho no es descabellado si pensamos que en esta época los trinitarios de la Provenza o los capuchinos del norte de Italia solían acudir al crédito para obtener el dinero que necesitaban en sus tratos ${ }^{36}$.

Es cierto que el tenue apoyo económico-institucional de los monarcas franceses a los religiosos de la Merced y la Trinidad tuvo su reflejo en un menor número de redenciones y cautivos libertados que sus homónimos españoles ${ }^{37}$. Ahora bien, esta mínima intervención regia permitió que los redentores franceses disfrutaran de más autonomía negociadora que los redentores españoles, quienes incluso llegaron a ir acompañados de un escribano público que se encargaba de velar por el cumplimiento de las instrucciones regias. Sólo disponemos de datos sociológicos del $40 \%$ de los cautivos libertados por los trinitarios y los mercedarios franceses entre 1539 y 1692, pero éstos nos muestran que el 38,8\% eran población civil masculina de las diócesis (Arles, Bayona, Coutances, Marsella, Rouen, Sables d'Olonne, etc.,) de donde ambas órdenes religiosas extraían el dinero para financiar sus operaciones. El 1,2\% restante eran mujeres, lo que significa que fueron apresadas en una cifra menor que los hombres, ya que por esta época embarcaban menos que ellos y no desempeñaban oficios con riesgo de captura, pero, sobre todo, que los propietarios musulmanes no las vendían ni siquiera por elevadas sumas de dinero ${ }^{38}$.

${ }^{34}$ BNF, F-5.001 (92), BNF, F-23.611 (549).

35 R. GRIMALDI-HIERHOLTZ, L'ordre des Trinitaires..., pp. 70-71.

36 W. KAISER, «Les 'hommes crédit' dans les rachats de captifs provençaux, XVle-XVIle siècles», en Les intermédiaries..., (mi agradecimiento al autor por proporcionarme una copia de su interesante trabajo).

${ }_{37}$ Los religiosos de la Trinidad y la Merced franceses rescataron 1.345 cautivos en 18 redenciones efectuadas entre 1539 y 1696, mientras que las mismas órdenes religiosas en España rescataron 6.369 cautivos en 43 redenciones efectuadas de 1575 a 1692.

${ }^{38}$ BNF, Ld. 43-5, 43-18, 43-19, 43-30, 43-35, 44-3, 44-4, 44-6, 44-8. 
La llegada de la «nave de la redención» a cualquiera de los puertos norteafricanos de esta época era anunciada con una salva de cañonazos ${ }^{39}$. Tanto si se atracaba de día como si se hacía de noche, el capitán del navío en el que viajaban los redentores estaba obligado a retener a la tripulación y a los pasajeros durante veinticuatro horas. Hasta el día siguiente no se entablaban las negociaciones de rescate, lo que se hacía en la sede del duán o consejo de gobierno, y siempre después de que los redentores fueran visitados por una comitiva de recibimiento formada por un letrado musulmán, el cónsul europeo de la zona, el «guardián del puerto" (se encargaba de inmovilizar el barco para que ningún cautivo, musulmán o judío pudiera embarcarse en ella durante el tiempo que duraban las negociaciones de rescate) y un «truchimán» o intérprete. Después de cotejar el pasaporte que autorizaba la entrada en el norte de África, los redentores eran acompañados hasta la "casa de la limosna», que era una especie de residencia donde depositaban el dinero de los rescates bajo la vigilancia de una escolta cristiana y musulmana.

Las negociaciones de rescate casi siempre superaban el tiempo estimado por los religiosos porque las autoridades musulmanas solían presionarles para que únicamente rescataran a aquellos cautivos que eran de su propiedad, y no a todos aquellos que los religiosos tenían pensado libertar en un principio ${ }^{40}$. La redención efectuada en Argel en 1644 proporciona un buen ejemplo de lo indicado, pues los religiosos fueron obligados a rescatar a un alto precio a 53 cautivos (casi el $43 \%$ del total de la redención) que no querían y que eran propiedad del Aga o Jefe de la milicia de $\operatorname{Arge}^{41}$. Las coacciones señaladas demuestran que los redentores no dudaron de la fiabilidad del sistema negociador, sino de la naturaleza de algunos de sus actores. Había que estar muy atento para no ser engañado por los propietarios de cautivos berberiscos. Dos de las trampas más generalizadas en esta época eran incitar a rescatar cautivos que previamente habían acordado con su propietario renegar nada más ser comprados, y hacer pasar por cautivos sanos a personas con enfermedades infecciosas o mentales.

Más seguro para los religiosos era tratar sus rescates directamente con judíos afincados en el norte de África y dedicados a este lucrativo comercio desde que fueron expulsados del sur de Europa a mediados del siglo XV. Abraham Mexía, Jacob Crudo y Moisés Bençamero son sólo algunos de los muchos nombres de judíos que se pueden recoger en la documentación consultada y que, en calidad de propietarios de cautivos, decidieron negociar con los redentores incluso cuando la situación política del norte de África era harto inestable para ellos. Pero no fueron los únicos. En ciudades como Orán, con una gran masa de soldados prisioneros de los berberiscos debido a las cabalgadas (expediciones de saqueo terrestres practicadas por huestes armadas de cristianos y musulma-

39 G. GómEZ DE LosAdA, Escuela de trabajos..., folios 478-482.

40 BNF, Ld. 43-19.

41 BNF, Ld. 44-2. 
nes), era costumbre desde principios del siglo XVI que los familiares de los cautivos libertaran a sus seres queridos con la intermediación de los numerosos mercaderes judíos que habitaron en la plaza española hasta 1669, fecha de su expulsión ${ }^{42}$.

El precio de los cautivos dependía del sexo, la edad, el oficio, etc. Las mujeres, los niños y los cautivos que anteriormente a su captura habían sido pilotos de barcos, oficiales del ejército y maestros fundidores tenían precios más elevados que el resto de los cautivos, del orden de dos, tres y hasta diez veces más que el precio que se pagaba por un cautivo cualquiera. Hay muchos ejemplos de todo ello, pero resulta especialmente esclarecedor el que proporciona el capitán Rafael Carmona, un gaditano de 46 años apresado en el puerto de Salé «por cinco galeras y dos fragatas de moros y turcos", y cuyo precio de rescate fue de 18.218 reales en 1642, casi catorce veces más que lo que pagaban los religiosos en esta época ${ }^{43}$. Cuando se prescindía de las características físicas, las cualidades y la condición social, el precio del cautivo variaba según hubiera un mayor o menor número de retenidos en el interior de los baños. La ciudad de Argel entre 1690 y 1729 puede servirnos de ejemplo, ya que el precio medio del cautivo pasó de 400 libras a 1.500 debido al paulatino descenso que sufrieron las capturas ${ }^{44}$. Este precio, que denominaremos «natural», podía verse incrementado con fuertes aranceles y tasas. En los puertos de Marruecos esto no solía ocurrir, pero sí en el puerto de Argel. En esta ciudad las redenciones pagaban a la entrada del puerto una cantidad que era resultado de gravar el cargo o activo que llevara la redención con un porcentaje fluctuante entre el 5 y el 11,5\%, según las épocas ${ }^{45}$.

El regreso de los religiosos con los cautivos rescatados todavía podía demorarse más de lo que ya había tenido lugar al antojo del «guardián del puerto», de cualquiera de los musulmanes principales que participaban en el gobierno del territorio e incluso del «guardián-basci». Las ofrendas de regalos ${ }^{46}$ agilizaban el embarque de toda la expedición redentora y garantizaba cierta impunidad hasta avistar las costas europeas, por lo que los mercedarios y los trinitarios siempre llevaron para esta finalidad importantes lotes de mercancías (tabaco, cochinilla, chocolate, seda, paños de calidad y perlas) procedentes de las posesiones españolas en América y compradas en diversas plazas (Toledo, Sevilla, Granada, Rouen, Marsella $)^{47}$.

42 B. VinCENT, «Juifs et esclavage à Oran», en M. GARcía-ARENAL (dir.), Entre el Islam y Occidente. Los judíos magrebíes en la Edad Moderna, Madrid, Casa de Velázquez, 2003, pp. 245-252.

43 J. A. Martínez Torres, Prisioneros de los infieles..., pp. 144-145.

44 J. MATHIEZ, «Trafic et prix de l'homme en Méditerranée aux XVIle et XVIIle siècles», Annales ESC, 2, (1954), pp. 157-164.

45 E. G. Friedman, Spanish Captives in North Africa in the Early Modern Age, Wisconsin, Wisconsin University Press, 1983, p. 124.

46 C. WINDLER, «Présents ou tributs», en La Diplomatie comme expériencie de l'autre. Consuls français au Magreb (1700-1840), Ginebra, Droz, 2002, pp. 485-548.

47 I. TURNAU, «La bonneterie en Europe du XVle au XVIIle siècle», Annales ESC, (1971), pp. 11181132. 
En los puertos de España y Francia una Junta sanitaria vigilaba que ninguno de los cautivos rescatados portara enfermedades infecciosas ${ }^{48}$. El miedo al contagio de peste procedente de Oriente fue tan frecuente entre las poblaciones del Mediterráneo español y francés que no faltan casos de navíos de la redención alejados de los puertos a cañonazos ${ }^{49}$. Si los cautivos venían enfermos pasaban cuarentena en lazaretos alejados de las poblaciones de desembarco. Por el contrario, si los cautivos venían sanos podían optar por regresar con los redentores hasta Madrid o París, donde se hacían importantes procesiones en las que participaban todos los sectores de la sociedad de la época. En este punto en particular también existieron diferencias notables entre España y Francia, mientras que las ceremonias españolas apostaron por una escenografía y liturgia sobria, las francesas hicieron uso de un notable ambiente festivo donde no faltaban la música, las luminarias y el acompañamiento de las personas rescatadas por unos niños ricamente vestidos de ángeles ${ }^{50}$.

Ningún precepto obligaba a los cautivos rescatados a regresar con los redentores a Madrid o París. Tanto a los que decidían marcharse como a los que no, los redentores les entregaban ropa y una "carta de franqueza» (tenía un período de validez de seis meses) rubricada por los soberanos de España o Francia a fin de que los autoridades de los pueblos cercanos a las zonas de desembarco no los tomaran por vagabundos y los enviasen a remar a las galeras reales ${ }^{51}$. Comenzaba una nueva historia para las personas rescatadas, y dicha historia en muchos casos podía ser más dramática que la que ya había tenido lugar. No hay estudios en esta desatendida línea de estudio, pero las cartas de ex cautivos que existen en los archivos españoles solicitando de los monarcas la vuelta a las guarniciones de la costa española e italiana, donde muchos de ellos habían sido capturados por los corsarios berberiscos, prueban que, en no pocos casos, era mejor volver a tentar la suerte de ser capturado que no vivir en unas poblaciones donde no tenían trabajo, familiares ni medios para subsistir.

\section{CONCLUSIÓN}

Al principio de este trabajo indicamos que las cancillerías europeas no pasaron por alto las numerosas solicitudes de rescate que cursaron los miles de europeos retenidos en las costas de Berbería durante la Edad Moderna. Es cierto que los máximos responsables de los gobiernos europeos más perjudicados por las razzias berberiscas no mantuvieron una política exterior contra las ciudades corsarias

48 D. PANZAC, Quarantaines et Lazarets. L'Europe et la peste d'Orient, Aix-en-Provence, Édisud, 1986.

49 BNM, mss., 2.727.

50 C. DE LA VERONNE, "Quelques processions de captifs en France a leur retour du Maroc, d'Algérie ou de Tunis (XVIle-XVIIle siècle)", Revue de l'Occident Musulman et de la Méditerranée, 8, (1970), pp. 131142.

51 A. ZYSBERG, Les Galériens: vie et destins de 60.000 forçats sur les galères de France, 1660-1748, París, Seuil, 1987. 
del norte de África capaz de cortocircuitar la hemorragia de población civil y militar capturada por los marinos musulmanes, sino que optaron, con la ayuda de la Iglesia católica y anglicana, por recuperar la mayor suma posible de hombres y mujeres gracias a la reorganización y la creación de instituciones de rescate cuyos orígenes se retrotraían en muchos casos a la Edad Media.

Las condiciones de vida de los europeos en los baños norteafricanos fueron extraordinariamente duras; no obstante, distaron mucho de esa imagen de campo de concentración nazi o gulag soviético que, a finales de las décadas de los setenta del pasado siglo XX, divulgaron algunos historiadores basándose exclusivamente en textos e imágenes elaboradas en el pasado en las imprentas de las órdenes redentoras ${ }^{52}$. Es cierto que los berberiscos aplicaron crueles castigos a los cautivos. También es verdad que los baños no cumplían las condiciones higiénicosanitarias óptimas para la retención de personas. Sin embargo, por lo que ya sabemos sobre los maltratos que se aplicaban a los esclavos musulmanes que bogaban en una galera pontificia o extraían mineral en los yacimientos del sur de Europa, resulta inexplicable que sigamos tachando de «bárbaras» a civilizaciones distintas a la nuestra por realizar prácticas que eran comunes en esta época, indistintamente del credo que se profesase ${ }^{53}$.

El grado de intervención de los monarcas franceses en las negociaciones de rescate de los religiosos de la Merced y la Trinidad fue menor que el de sus homónimos españoles. Probablemente porque, a diferencia de España, Francia disponía desde el siglo XVI de un eficaz despliegue diplomático en las principales poblaciones berberiscas, capaz de obtener la rápida liberación de capitanes de barcos, marinos y soldados apresados en el Mediterráneo ${ }^{54}$. No es descabellado indicar, por tanto, que las redenciones religiosas progresaron hacía una laicización gradual de manos del monarca y sus representantes políticos, si bien el grado de intervención regia se supeditó a la importancia jugada por el Mediterráneo en la política exterior de cada Monarquía.

Hay que indicar, finalmente, que las negociaciones de rescate de los religiosos de la Merced y la Trinidad causaron cierta decepción entre la población europea de la época, pues no siempre se rescataban aquellas personas que tenían más riesgo de ser absorbidas por el Islam, tal era el caso de las mujeres y los niños. Haciendo uso de las palabras empleadas por el anónimo autor del Discurso cristiano y político sobre la redención de cautivos (s.d.), lo verdaderamente esencial en los rescates efectuados por los mercedarios y los trinitarios era la salvación del alma y

52 S. CLISSOLD, The Barbary Slaves, Londres, Paul Elek, 1977, p. 56.

53 S. Bono, Schiavi musulmani nell'Italia moderna. Galeotti, vu' cumprà, domestici, Nápoles, Edizioni Scientifiche Italiane, 1999; A. StelLA, Histoires d'esclaves dan la péninsule ibérique, París, École des Hautes Études en Sciences Sociales, 2000.

${ }^{54}$ W. KAISER, «Négocier la liberté. Missions françaises pour l'échange et le rachat de captifs au Maghreb (XVIle siècle)", en C. MOATTI (dir.), La mobilité des personnes en Méditerranée de l'Antiquité à l'époque moderne, Rome, École française de Rome, 2005, pp. 501-528. 
el acercamiento a Dios mediante el sufrimiento ${ }^{55}$. Por eso, el regreso de aquellas personas que habían permanecido fieles a los dictados de la Iglesia católica en el tradicional enfrentamiento de «la luz con las tinieblas» se celebraba, aunque en la mayoría de los casos no fueran las demandadas por los oferentes de limosnas, en importantes procesiones ${ }^{56}$.

55 BNM, mss., 3.865.

56 Ibidem. 